\title{
Overexpression of Erianthus arundinaceus DREB2 Transcription Factor Ameliorates the Salinity and Drought Tolerance in Eleusine coracana Cultivars ${ }^{\dagger}$
}

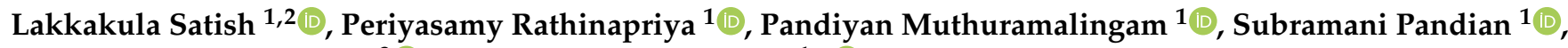 \\ Stanislaus Antony Ceasar ${ }^{3}{ }^{10}$ and Manikandan Ramesh ${ }^{1, *(\mathbb{B}}$
}

1 Department of Biotechnology, Science Campus, Alagappa University, Karaikudi 630004, Tamil Nadu, India; pandu.pine@gmail.com (L.S.); rathina.priya25@gmail.com (P.R.); pandianmuthuramalingam@gmail.com (P.M.); pandiannsp7@gmail.com (S.P.)

2 Department of Biotechnology \& Engineering, The Jacob Blaustein Institutes for Desert Research, Ben-Gurion University of the Negev, Beer Sheva 84105, Israel

3 Department of Biosciences, Rajagiri College of Social Sciences, Cochin 683104, Kerala, India; antony_sm2003@yahoo.co.in

* Correspondence: mrbiotech.alu@gmail.com

+ Presented at the 1st International Electronic Conference on Plant Science, 1-15 December 2020; Available online: https://iecps2020.sciforum.net/.

Citation: Satish, L.; Rathinapriya, P.; Muthuramalingam, P.; Pandian, S.; Ceasar, S.A.; Ramesh, M. Overexpression of Erianthus arundinaceus DREB2 Transcription Factor Ameliorates the Salinity and Drought Tolerance in Eleusine coracana Cultivars. Biol. Life Sci. Forum 2021, 4, 8. https://doi.org/ 10.3390/IECPS2020-08665

Published: 1 December 2020

Publisher's Note: MDPI stays neutral with regard to jurisdictional claims in published maps and institutional affiliations.

Copyright: (c) 2020 by the authors. Licensee MDPI, Basel, Switzerland. This article is an open access article distributed under the terms and conditions of the Creative Commons Attribution (CC BY) license (https:// creativecommons.org/licenses/by/ $4.0 /)$.

\begin{abstract}
Drought and salinity are the major constraints on agricultural production worldwide and a remarkable attempt is being made to improve the plant yields in the direction of increasing water deficit. We have developed transgenic finger millet cultivars ' $\mathrm{CO}(\mathrm{Ra})-14^{\prime}$ and 'Paiyur-2' overexpressing Erianthus arundinaceous DREB2 (EaDREB2) transcription factor confirmed by PCR and Southern stably expressed in $\mathrm{T}_{0}$ and $\mathrm{T}_{1}$. These transgenic lines were tolerant to high salinity and severe drought stress conditions without affecting the morphological or agronomic characters. Analysis of morpho-physiological characters revealed that overexpression of EaDREB2 gene was associated with maintenance of chlorophyll content, increased relative water content, improved accumulation of the osmotic substance such as proline and decreased electrolyte leakage, under both saline and drought stresses. After treating the plants to progressive drought and salinity stress, transgenic lines showed less chlorophyll reduction and moderate growth inhibition than the controls. The majority of the transformed lines showed prominent tolerance to salinity and drought with significant spikelet fertility and higher grain yield compared to the controls at stressed and unstressed conditions. This is the first holistic report on development of drought and saline tolerance in finger millet through transgenic modification and it is essential to benefit the farmers from seasonal stress.
\end{abstract}

Keywords: abiotic stress; Agrobacterium; drought tolerance; EaDREB2 gene; finger millet transformation; physiological characters; saline tolerance

\section{Introduction}

The objective of the present study was to establish the role of Erianthus arundinaceus $D R E B 2$ (EaDREB2) gene in conferring abiotic stress tolerance in transgenic finger millet plants. EaDREB2 gene was isolated from plant source and its expression was analyzed under different abiotic stresses, such as salinity and water deficit stress where the droughtresponsive transgenic plants were generated, showing significant tolerance to salinity and dehydration stresses.

\section{Experiments}

The collected DREB gene sequences were named OsDREB, TaDREB, TtDREB, PgDREB, GmDREB, AsDREB, ScDREB, SiDREB, SbDREB and ZmDREB. These DREB genes sequence 
set were then uploaded into MEGA v7.0 [1] and MSA (multiple sequence alignment) was performed.

For Agrobacterium-mediated transformation of finger millet, we have used the same method reported by us recently for the tissue culture, transformation and regeneration of finger millet cultivars [2,3]. PCR was used to confirm the presence of EaDREB2 gene in hygromycin resistant plants. Genomic DNA was isolated using $100 \mathrm{mg}$ of fresh leaves from hygromycin resistant $\left(\mathrm{T}_{0}\right.$ and $\left.\mathrm{T}_{1}\right)$ and control (un-transformed) plants using the CTAB (N-Cetyl-N,N,N-trimethyl ammonium bromide) method [4]. The EaDREB2 gene specific primers (forward 5'CAAGTGGTGGAAGGAGCAGA3' and reverse $5^{\prime}$ CACTAGATGCCAGCAACGAA3') (Sigma Aldrich, St. Louis, MO, USA) were used for PCR. The plants confirmed by PCR were further analyzed for transgene copy number through Southern blotting.

For abiotic stress treatments, seeds collected from $\mathrm{T}_{1}$ lines were grown for four weeks in biosafety greenhouse. Four-week-old wild plants and $\mathrm{T}_{2}$ transgenic finger millet plants were subjected to various abiotic stress treatments. Finger millet plants exposed to saline and drought stress were analyzed for growth parameters root, fresh weight (FW) and dry weight (DW) of shoot and roots, number of tillers and roots and length of tillers and primary roots. Many physiological parameters such as total chlorophyll (Chl) content, relative water content (RWC), electrolyte leakage $\left(\mathrm{E}_{\mathrm{L}}\right)$, proline content, hydrogen peroxide $\left(\mathrm{H}_{2} \mathrm{O}_{2}\right)$ level and caspase-like activity were analyzed at four different stages viz., before stress (BS), one week after the stress (1W), fifteen days after stress (2W) and a week after re-watering (ARW)for drought stress experiments. Similarly, all these physiological parameters were also analyzed in two different stages vegetative (VS) and reproductive (RS) each one and two weeks after exposure to saline stress. Total Chl content $(\mathrm{Chl} a+b)$ was according to Lichtenthaler [5]. For RWC assessment, leaves were submerged for overnight in deionized water for swelling, then the samples were air dried and weighed (SW). Then, these leaves were oven dried at $70{ }^{\circ} \mathrm{C}$ for $48 \mathrm{~h}$ and dry weights (DW) were measured. The RWC was calculated according to the formula: RWC $(\%)=[(\mathrm{FW}-\mathrm{DW}) /(\mathrm{SW}-\mathrm{DW})] \times 100$.

The $E_{L}$ in the leaf samples were assayed according to the method described previously (Satish et al. 2016c). The electrolyte leakage $\left(E_{L}\right)$ was calculated as a percentage of electrolytes leaked from cut cells compared to the total electrolyte pool $\left(\mathrm{E}_{\mathrm{T}}\right)$ in the test [6]. Relative electrolyte leakage $\mathrm{E}_{\mathrm{L}}(\%)=\left(\mathrm{E}_{\mathrm{I}} / \mathrm{E}_{\mathrm{T}}\right) \times 100$

For estimation of proline content, $500 \mathrm{mg}$ each leaf samples in fresh weight was randomly collected and quantified according to Bates et al. (1973) [7]. $\mathrm{H}_{2} \mathrm{O}_{2}$ content was estimated based on a procedure reported by del Pozo and Lam (1998) [8]. The caspaselike activity was measured at $405 \mathrm{~nm}$ absorbance for every $20 \mathrm{~min}$ during the incubation phase [8].

All the analyses were performed in triplicate. Plant tissues were collected from each pot at different stages before and after stress treatments. Data shown in the tables and text specify the mean \pm standard error (SE) values where $n=3$. Differences among salinity and drought stress treatments were evaluated and analyzed by one-way ANOVA, significance of divergence between means were determined at $p \leq 0.05$ according to Duncan's multiple range test through SPSS 17.0 version (IBM, SPSS Statistics) software.

\section{Results and Discussion}

Unrooted phylogenetic tree was imputed though MEGA v7.0 tool to evaluate the $D R E B$ gene members from various plant species and their respective phylogenetic organization. The phylogenetic tree of abiotic stress responsible $D R E B$ and their strong homology between the genes were significantly confirmed through phylogenetic analysis (Figure 1A). 

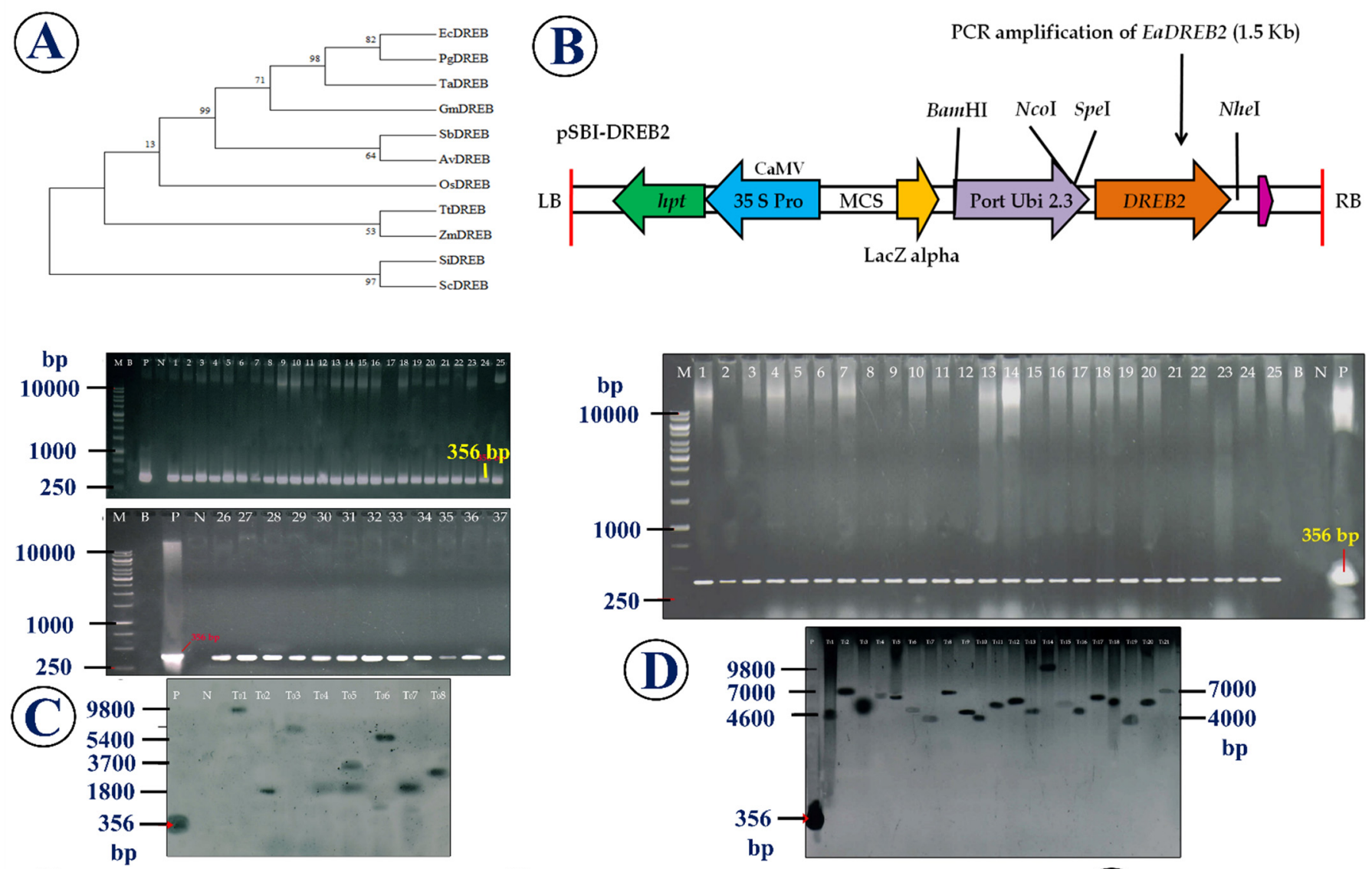

(E)
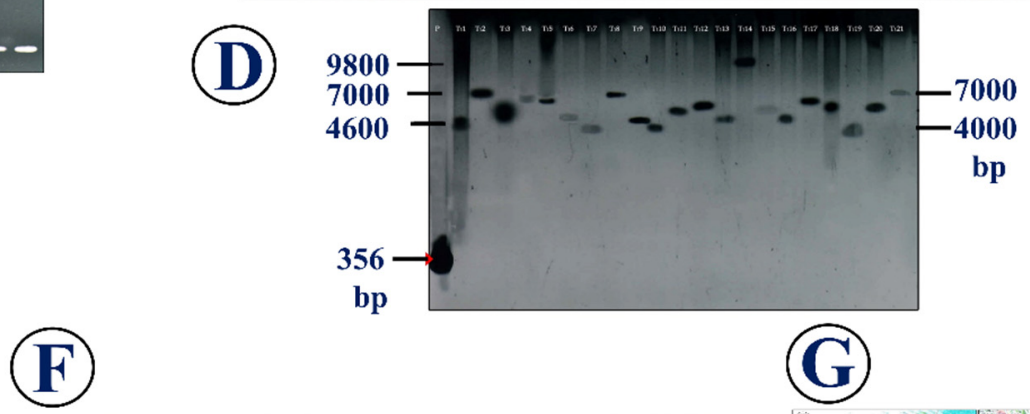

bp
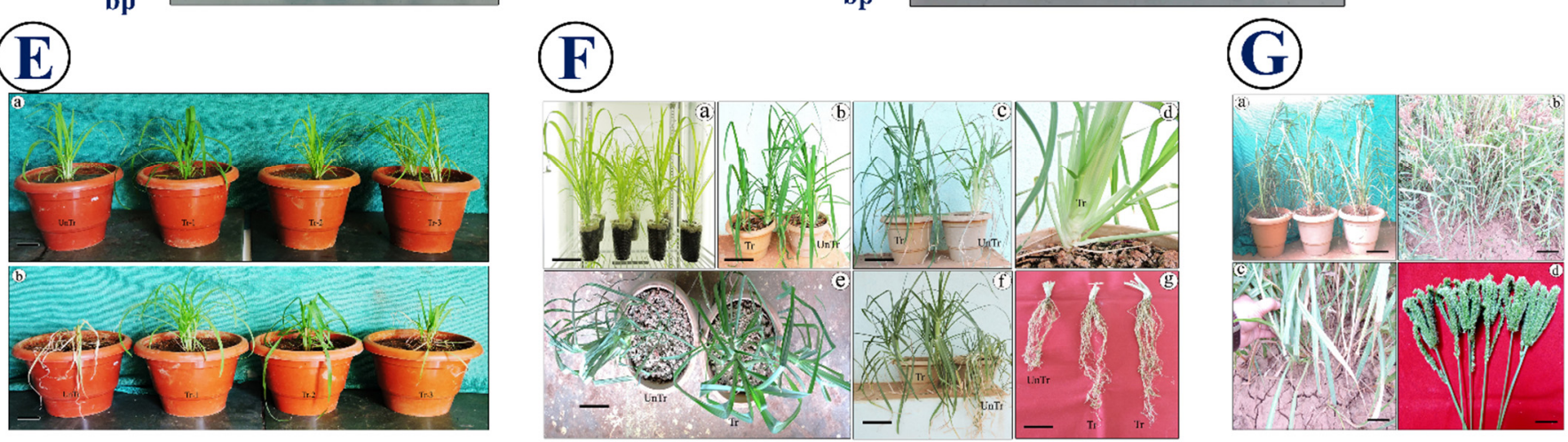

Figure 1. Overview of the DREB2 transformation and the salinity and drought tolerance in Eleusine coracana cultivars. (A) The phylogenetic tree of abiotic stress responsible DREB and their strong homology between other DREB genes; (B) Schematic diagram of the T-DNA region of pSBI with EaDREB2 gene; (C,D) PCR and Southern blot analysis of $\mathrm{T}_{0}$ and $\mathrm{T}_{1}$ lines of lines of finger millet; $(\mathbf{E}-\mathbf{G})$ Evaluation of finger millet transgenic lines expressing EaDREB2 gene and un-transformed control plants under salinity and drought stress conditions.

Thirty-seven independently transformed hygromycin resistant plants (both ' $\mathrm{CO}(\mathrm{Ra})$ 14 ' and 'Paiyur-2' cultivars) showed the desired PCR product of $356 \mathrm{bp}$ with EaDREB2 gene specific primers (Figure 1B-D). Southern blot analysis of eight putative transgenic lines from both cultivars showed integration of $E a D R E B 2$ gene with varied copy numbers (Figure 1D).

Under saline $(100 \mathrm{mM} \mathrm{NaCl})$ treatment, control plants started wilting from the third day onwards, whereas transgenic plants integrated with EaDREB2 gene did not show any symptoms of wilting and they were healthy when compared to un-transformed plants and look similar to the unstressed wild plants (Figure 1E). Both un-transformed control and transformed finger millet lines of ' $\mathrm{CO}(\mathrm{Ra})-14$ ' and 'Paiyur-2' showed significant biomass dif- 
ferences after two weeks of salinity treatment. In drought stress experiments, control plants started wilting from the third day onwards, whereas transgenic plants integrated with EaDREB2 gene did not show any symptoms of wilting and they were healthy when compared to un-transformed plants and look similar to the unstressed wild plants (Figure 1F,G). Therefore, we concluded that EaDREB2 overexpression increases the drought and saline tolerance of transgenic finger millet.

\section{Conclusions}

In this study, EaDREB2 gene was successfully transformed in to finger millet cultivars ' $\mathrm{CO}(\mathrm{Ra})-14^{\prime}$ ' and 'Paiyur-2' and carried out phenotyping assays to distinguish highperformance transgenic lines under realistic greenhouse screening. All the transgenic lines were evaluated based on the high survival of transgenic plants after severe salinity and drought stress treatments under greenhouse conditions. These results suggested that the improved survival of the finger millet transgenic lines after severe salinity and drought stress conditions could be associated with either the activation of genes related to salinity and drought resistance or another conservative growth pattern in the transgenic compared with un-transformed plants.

Author Contributions: L.S. and M.R. conceived and designed the experiments; L.S. performed the experiments; L.S., P.R., P.M. and S.P. analyzed the data; M.R. contributed reagents/materials/analysis tools; L.S. wrote the original paper; S.A.C. and M.R. critically reviewed the manuscript and revised. All authors have read and agreed to the published version of the manuscript.

Funding: This research received no external funding.

Institutional Review Board Statement: Not applicable.

Informed Consent Statement: Not applicable.

Acknowledgments: We thank the Department of Small Millets, Millet Research Station, Tamil Nadu Agricultural University, Coimbatore, India for providing seed material used in this study. We also acknowledge N. Subramonian, Principal Scientist, Sugarcane Breeding Institute (ICAR), Tamil Nadu, India for providing gene material used in this study. The authors also thankfully acknowledge DST-FIST (Grant No. SR/FST/LSI-639/2015(C)), UGC-SAP (Grant No.F.5-1/2018/DRSII (SAP-II)) and DST-PURSE (Grant No. SR/PURSE Phase 2/38 (G)) for providing lab facilities. The authors also thank RUSA 2.0 [F. 24-51/2014-U, Policy (TN Multi-Gen), Dept of Edn, GoI].

Conflicts of Interest: The authors declare no conflict of interest.

\section{Abbreviations}

DREB, Dehydration responsive element binding; hpt, Hygromycin phosphotransferase; MS, Murashige and Skoog; SAMs, Shoot apical meristems.

\section{References}

1. Kumar, S.; Stecher, G.; Tamura, K. MEGA7: Molecular Evolutionary Genetics Analysis Version 7.0 for Bigger Datasets. Mol. Biol. Evol. 2016, 33, 1870-1874. [CrossRef]

2. Satish, L.; Ceasar, S.A.; Shilpha, J.; Rency, A.S.; Rathinapriya, P.; Ramesh, M. Direct plant regeneration from in vitro-derived shoot apical meristems of finger millet (Eleusine coracana (L.) Gaertn.). In Vitro Cell. Dev. Biol. Plant 2015, 52, 192-200. [CrossRef]

3. Satish, L.; Ceasar, S.A.; Ramesh, M. Improved Agrobacterium-mediated transformation and direct plant regeneration in four cultivars of finger millet (Eleusine coracana (L.) Gaertn.). Plant Cell Tissue Organ Cult. 2017, 131, 547-565. [CrossRef]

4. Doyle, J.J.; Doyle, J.L. Isolation of plant DNA from fresh tissue. Focus 1990, 12, 39-40.

5. Lichtenthaler, H.K. Chlorophylls and carotenoids: Pigments of photosynthetic biomembranes. Methods Enzymol. 1987, 148, 350-382.

6. Tabot, P.T.; Adams, J.B. Early responses of Bassia diffusa (Thunb.) Kuntze to submergence for different salinity treatments. S. Afr. J. Bot. 2013, 84, 19-29. [CrossRef]

7. Bates, L.S.; Waldren, R.P.; Teare, I.D. Rapid determination of free proline water stress studies. Plant Soil 1973, 39, $205-207$. [CrossRef]

8. del Pozo, O.; Lam, E. Caspases and programmed cell death in the hypersensitive response of plants to pathogens. Curr. Biol. 1998, 8, 1129-1132. [CrossRef] 